ENCYCLOPÉDIE Encyclopédie berbère

BERBERE

$24 \mid 2001$

24 | Ida - Issamadanen

\title{
Idris $\mathrm{I}^{\mathrm{er}}(788-791)$
}

E.B.

\section{OpenEdition}

Journals

Édition électronique

URL : http://journals.openedition.org/encyclopedieberbere/1524

DOI : 10.4000/encyclopedieberbere. 1524

ISSN : 2262-7197

\section{Éditeur}

Peeters Publishers

\section{Édition imprimée}

Date de publication : 1 octobre 2001

Pagination : 3633-3635

ISBN : 2-7449-0207-1

ISSN : 1015-7344

\section{Référence électronique}

E.B., « Idris ler (788-791) », Encyclopédie berbère [En ligne], 24 | 2001, document I20, mis en ligne le 01 juin 2011, consulté le 24 septembre 2020. URL : http://journals.openedition.org/encyclopedieberbere/ 1524 ; DOI : https://doi.org/10.4000/encyclopedieberbere.1524

Ce document a été généré automatiquement le 24 septembre 2020

(c) Tous droits réservés 


\section{Idris $I^{\mathrm{er}}(788-791)$}

E.B.

1 Descendant du Prophète, par Ali, Idris ben Abdallah eut une vie agitée et fut l'ancêtre d'une dynastie chérifienne implantée dans le Maghreb extrême, tandis que les Aghlabites étaient maîtres de l'Ifriqiya et que les Rostémides régnaient sur le Maghreb central. Ce n'était pas la première fois que l'Afrique du Nord se trouvait tronçonnée en trois embryons d'État. La province d'Africa des Romains correspondait à peu près à l'Ifriqiya des Arabes, la Maurétanie césarienne s'identifie au Maghreb central, tandis que la Maurétanie tingitane correspond au Maghreb el-aqça, l'Extrême Occident du monde musulman. Ces trois provinces romaines devaient leur découpage à un découpage antérieur de la Berbérie en royaumes massyle, masaesyle et maure.

2 Le cas d'Idris $\mathrm{I}^{\mathrm{er}}$ présente toutefois un aspect particulier : cet Oriental, cet Arabe, ne disposait au début de sa carrière d'aucun concours des Berbères ; c'est en réfugié sans ressources, accompagné de son fidèle Rachid, qu'il atteint Tanger en 780 après avoir traversé le Hédjas, l'Égypte, et l'Afrique du Nord. Il est probable que l'Alide sut faire valoir auprès des Berbères gagnés au kharédjisme* ses qualités de chérif et qu'il sut jouer de la violente hostilité que kharédjites et chiites portaient à l'égard des sunnites que protégeaient les Aghlabites et leur maître, le calife de Bagdad.

3 Arrivé à Tanger, Idris était aux portes du califat des Omeyyades d'Espagne dont les origines étaient fort semblables à ses propres aventures. Omeyyades et Alides avaient le même ennemi, le calife abbasside qui ne pouvait compter que sur la fidélité des gouverneurs aghlabites de Kairouan. Entre le Maghreb extrême et les territoires ifriqiyens, le royaume des Rostémides issus des révoltes kharédjites du siècle précédent constituait un écran suffisamment protecteur pour le futur royaume idrisside. La quasitotalité du Maghreb central, le sud de l'Ifriqiya et le pays Nefoussa d'obédience kharédjite reconnaissaient la suzeraineté de l'imam Rostem, un Perse qui était, d'après ses partisans, lui aussi chérif. Comme leurs contemporains idrissides, les Rostémides créèrent leur capitale en fondant la ville de Tahert qui, jusqu'à la fin de la dynastie kharédjite, leur demeura fidèle. Dans cette ville austère, les mœurs et la vie commerciale obéissaient aux règles très strictes de l'ibadisme. 
Tanger ne convenait guère aux projets d'Idris. Il revient chez les Awreba qui occupaient la région de Volubilis et le massif du Zerhoun. Cette tribu berbère l'avait très bien accueilli et il fut entouré et choyé comme doit l'être un descendant du Prophète. Idris s'établit donc à Walila sur l'emplacement de Volubilis. Contrairement à ce que pensaient les premiers historiens du Maroc, Volubilis n'étaient pas encore un champ de ruines. Si la vie municipale s'était réduite, l'activité économique avait permis le maintien d'une vie citadine déjà en partie ruralisée comme le prouvent les très nombreuses huileries mises au jour lors des dernières fouilles. On en compte plus de cinquante dans les différents quartiers de la ville. Les travaux récents ont permis de corriger la vision pessimiste suggérée par les ruines. Bien que Walila fût plus étendue qu'on ne le pensait, Idriss chercha un nouvel emplacement pour y édifier la capitale dont il rêvait, une ville majeure qui serait le pendant occidental de Kairouan. Ce fut Fès* dont on attribua longtemps la fondation à son fils Idris II. Le progrès des connaissances permet aujourd'hui de reconstituer les différentes étapes de la construction de la ville. La fondation de 789 se serait faite sur l'emplacement de l'actuel quartier des Andalous; une palissade isola le camp qui occupait la partie orientale de Madina Fas. Un atelier monétaire faisant connaître ce nom fonctionnait dès 801.

Le Royaume idrisside à la mort d'Idris II

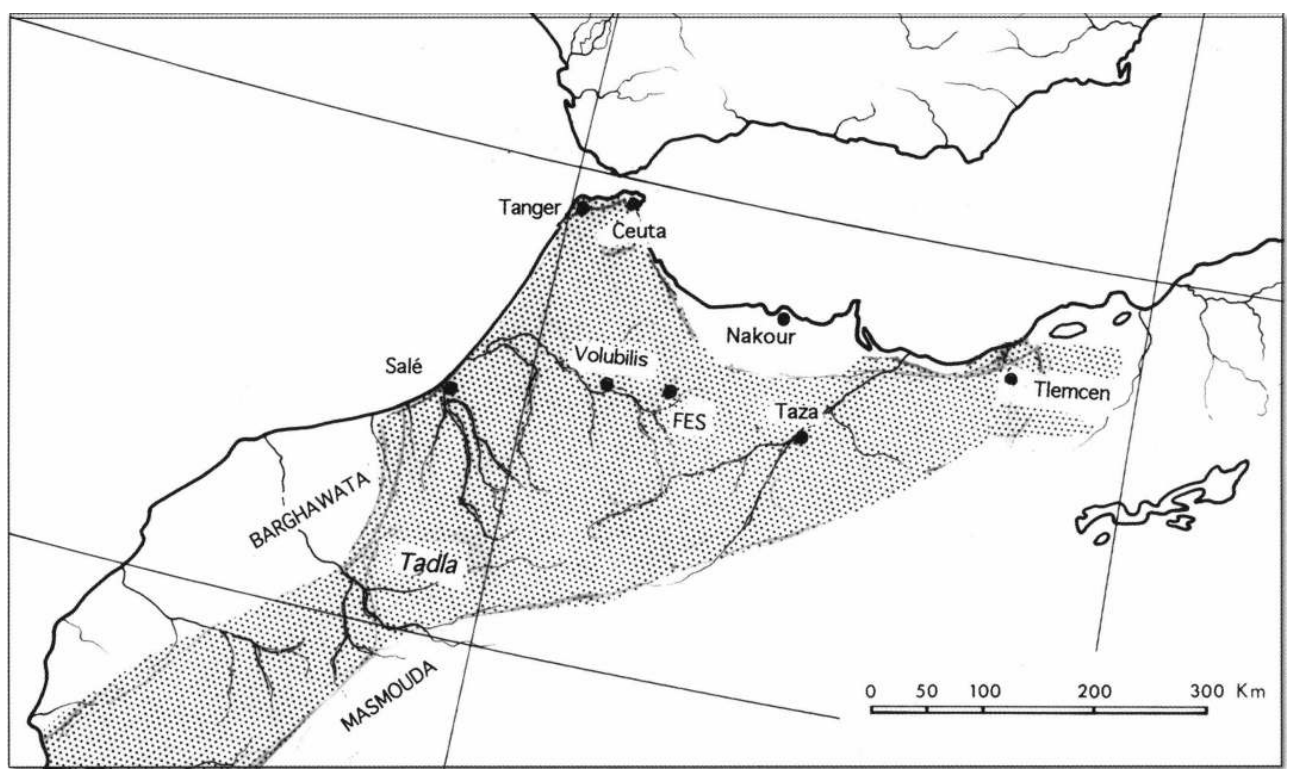

5 Idris $\mathrm{I}^{\mathrm{er}}$, fort de l'indéfectible alliance des Awreba, aurait rapidement, selon Ibn Khaldoun, pris le commandement d'une coalition de tribus localisées dans le nord du Maroc. Outre les Awreba*, qui constituaient le noyau central, les différentes sources citent les Zwawa*, les Zouagha, les Sedrata, les Ghiata*, les Nefza, les Miknasa*...

De cette coalition tribale, Idris $\mathrm{I}^{\text {er }}$ sut constituer un embryon d'État qui s'étendit largement vers le sud, l'ouest et l'est. Au sud du territoire initial, le domaine idrisside couvrit une part importante du Tamesna. D'autres campagnes entrânèrent la soumission de Chella à l'ouest et de Taza à l'est. Encore plus heureuse fut l'expédition contre Tlemcen, dont les Magraoua s'étaient emparés quelques années plus tôt (786), mettant fin au royaume des Beni Ifren. Ce nouveau domaine ne fut pas intégré au royaume idrisside, mais il en devint une sorte de boulevard confié à l'Idrisside Soleiman qui, selon les auteurs, serait soit un neveu soit un cousin, soit même un frère d'Idris I ${ }^{\mathrm{er}}$. 
7 La politique religieuse d'Idris demeure assez mystérieuse : si dans les siècles suivants, lui et ses premiers successeurs furent comptés parmi les champions de l'orthodoxie sunnite, il n'en demeure pas moins qu'après avoir bénéficié de concours chiites lors de son départ d'Orient, il fut unanimement qualifié de motazilite par les auteurs orthodoxes.

8 Idriss I $^{\text {er }}$ ne devait guère profiter de ses conquêtes. Le calife Haroun al Rachid, inquiet des progrès réalisés par Idris dans le lointain Maghreb, décida de le supprimer. L'arrêter et le faire juger à Bagdad paraissait trop risqué. Une grappe de raisin, préalablement empoisonnée, offerte par un prétendu réfugié mit fin aux projets du fondateur de la dynastie idrisside.

\section{BIBLIOGRAPHIE}

(voir Idris II)

INDEX

Mots-clés : Maroc, Moyen Âge, Personnage 